\title{
| Functional disparity of graft-derived T lymphocytes: experimental data
}

\begin{abstract}
Mikhail Y. Drokov, Elena N. Parovichnikova, Darya S. Dubnyak, Larisa A. Kuzmina, Irina V. Galtseva, Julia O. Davydova, Nikolay M. Kapranov, Vera A. Vasilyeva, Olga M. Koroleva, Ekaterina D. Mikhalcova, Natalia N. Popova, Tatyana V. Gaponova, Valentina N. Dvirnyk, Olga N. Baiteriyakova, Grigory A. Efimov, Alexander S. Vdovin, Valery G. Savchenko and CIC 930
\end{abstract}

National Research Center for Hematology, Ministry of Health, Moscow, Russian Federation

Contact: Dr.Mikhail Drokov

E-mail: mdrokov@gmail.com

\section{Introduction}

It is well known that bone marrow (BM) and peripheral blood stem cells (PBSC) have their advantages and disadvantages as the stem cell source. Median time of neutrophil recovery and hospitalization is shorter for PBSC than for $\mathrm{BM}$. On the other hand, rates of acute graft-versus-host disease (aGVHD) are lower in case of using BM as a stem cell source. Almost all authors explain it by different amount of T cells (CD3+ cells) in grafts, but less data is available about functional ability of these $\mathrm{T}$ cells. It may be assessed by the amounts of secreted cytokines. Superantigens (SAgs) cause a nonspecific activation of $\mathrm{T}$ cells by binding the $\mathrm{T}$ cell receptor (TCR), independently of certain V $\beta$ domains of TCR and crosslinking it to major histocompatibility complex (MHC) molecules of antigen presenting cell (APC). Due to this stimulation, CD4+ and CD8+ cells start to secrete effector cytokines and induce activation markers on their cell surface within few hours. Here we present preliminary data on functional assay (response to SAgs stimulation) of graft $\mathrm{T}$ cells obtained from healthy donors.

\section{Patients and methods}

Graft samples were collected from nine healthy donors (3 bone marrow samples and 6 PBSC specimens obtained after donor G-CSF stimulation ( $10 \mu \mathrm{g} / \mathrm{kg}$ for 5 days). Aliquotes of 106 cells in RPMI-1640 supplied with $10 \%$ of autologous serum were incubated with SAgs at a recommended concentration. For T lymphocyte stimulation, we used Cytostim reagent (Miltenyi Biotec, Germany). Brefeldin A was added at specified amounts 2 hours after stimulation, in order to block anterograde transport from endoplasmic reticulum to Golgi structures. The cells were then incubated for 4 hours at $37^{\circ} \mathrm{C}$, 5\% CO2. Anti-CD45-APC (BD, USA), anti-CD4-APC-Cy7
(BD, USA), anti-FoxP3-PerCP-Cy5.5 (BD, USA), anti-IL17A-PE (BD, USA), anti-CD294-FITC (Biolegend, USA), anti-INF- $\gamma$-PE-Cy7 and intracellular staining kit (Cytofix/Cytoperm, BD, USA) were used to determine $\mathrm{T}$ helper (Th) subpopulations (Fig. 1) (Th1:CD45+CD4+INF- $\gamma+$; Th2:CD45+CD4+CD294+; $\quad$ Treg:CD45+CD4+FoxP3+; Th17:CD45+CD4+IL-17A+). 30,000 of CD4+ cells were analyzed on a BD FACSCanto II (Becton Dickinson, USA) to achieve sufficient statistical power.

\section{Results}

As shown in Fig. 2 (left panel), all the bone marrow samples showed similar Th1:Th2:Treg:Th17 ratios, and did not functionally differ from normal peripheral blood (PB) samples. Almost all lymphocytes from bone marrow are presumed to originate from peripheral blood. Meanwhile, all the PBSC grafts had different Th1: Th2: Treg: Th17 ratios (Fig. 2, right panel). Due to wide use of CD34+ cell counts as a "universal index", and variability in total nucleated cells contents, we attempted to calculate the number of Th1, Th2, Treg, Th17 cells per 100 of CD34+ cells of grafts received by the patients. As shown in Fig.3 (right), appropriate Th1-, Th2-, Treg-, Th17to-CD34-ratios in PBSC proved to be quite variable. E.g., the relative numbers of Th cell subpopulation may vary up to 40 times from graft to graft.

\section{Conclusion}

In vitro stimulation of graft $\mathrm{T}$ lymphocytes with SAgs can reflect some events which are similar to those in vivo observed in graft $\mathrm{T}$ cells after infusion. They may be used as a model to study the effects of graft composition upon GVHD development, graft failure and other processes in which the graft $\mathrm{T}$ cell may participate. Our preliminary data demonstrate that 
functional profile of the graft-derived T lymphocytes shows an extreme intersample variability and, probably, may affect different processes occurring in PBSC recipients, including clinical outcomes of allo-HSCT. Disclosures: No relevant conflicts of interest to declare.

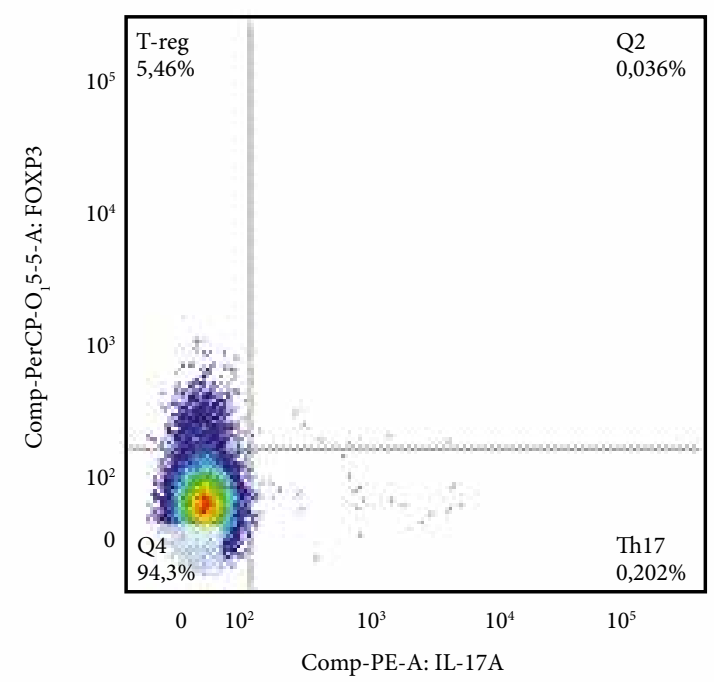

Figure 1: Gating strategy for Th subpopulations in PBSC

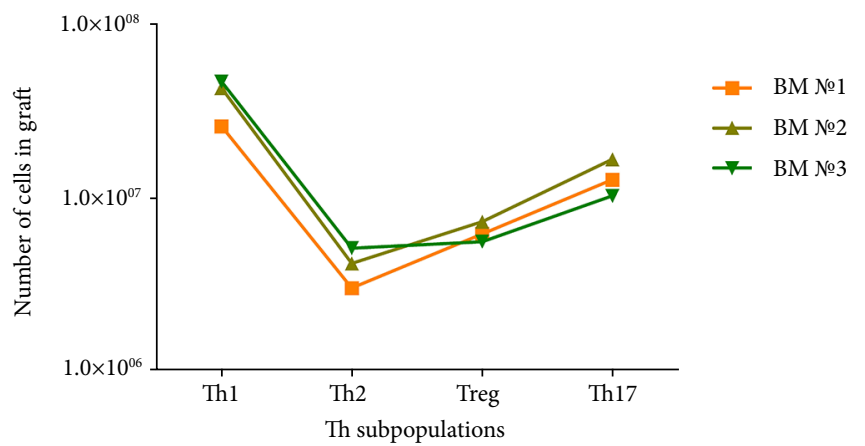

\section{Keywords}

Peripheral blood stem cells, bone marrow, graft, aGVHD, T helpers, Th17 cells, T regulatory cells, Th1, Th2.
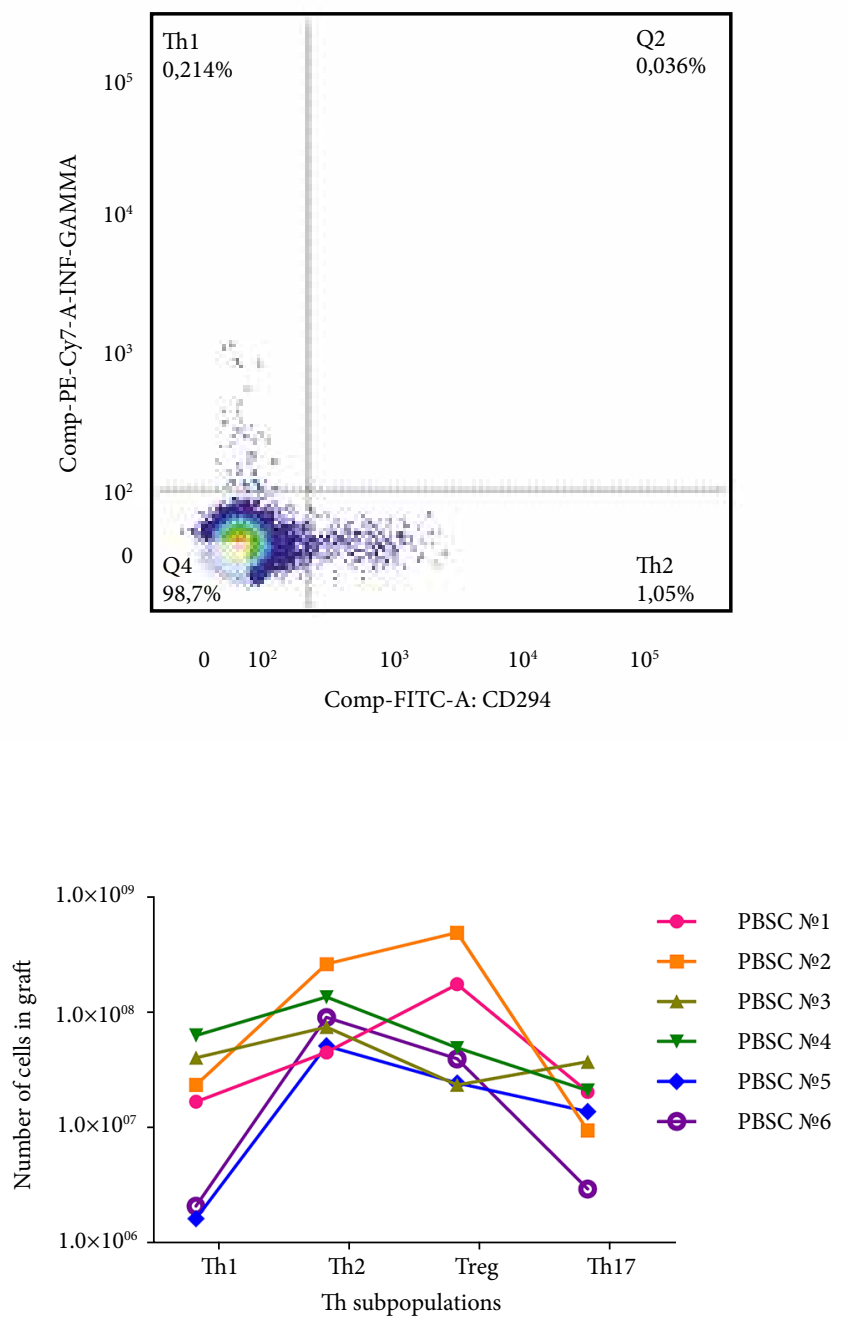

Figure 2: T helper subpopulation profile in bone marrow versus PBSC
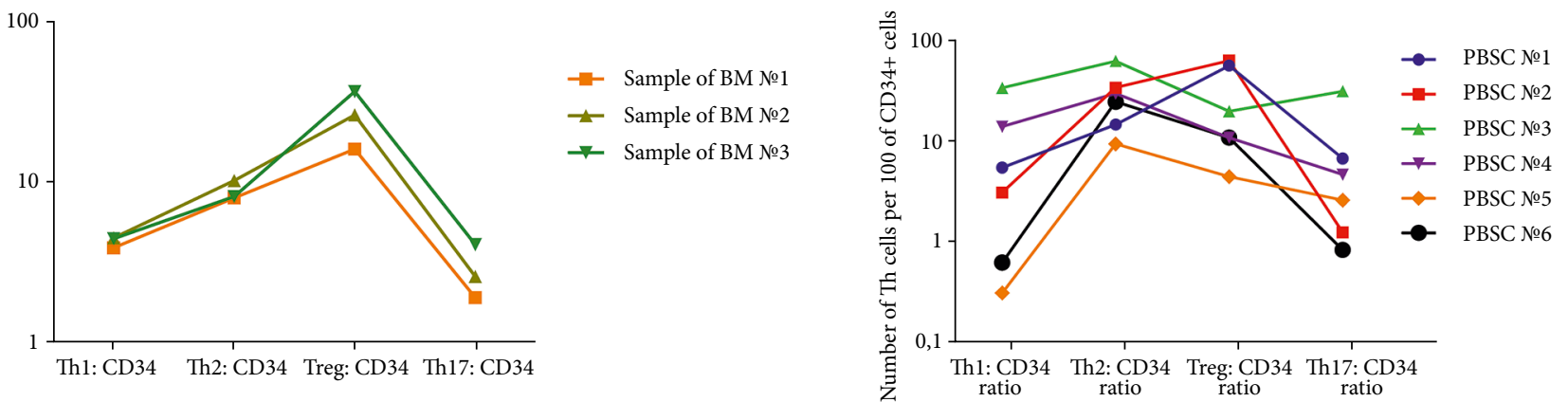

Figure 3: T helper subpopulation profile in bone marrow versus PBSC (per 100 CD34+ cells) 


\title{
| Функциональные различия в составе Т-лимфоцитов трансплантатов: экспериментальные данные
}

\author{
Михаил Ю. Дроков, Елена Н. Паровичникова, Дарья С. Дубняк, Лариса А. Кузьмина, Ирина В. Гальцева, Юлия О. Да- \\ выдова, Николай М. Капранов, Вера А. Васильева, Ольга М. Королева, Екатерина Д. Михальцова, Наталья Н. Попо- \\ ва, Татьяна В. Гапонова, Валентина Н. Двирнык, Ольга Н. Байтерякова, Григорий А. Ефимов, Александр А. Вдовин, \\ Валерий Г. Савченко
}

Федеральное государственное бюджетное учреждение Гематологический научный центр, Москва, Россия

\section{Введение}

Хорошо известен факт, что при использовании в качестве трансплантата мобилизованных стволовых клеток крови (СКК) время восстановления количества нейтрофилов значимо меньше, чем при использовании костного мозга (КМ). В то же время частота развития острой реакции трансплантат против хозяина (оРТПХ) значимо ниже при использовании КМ, чем при СКК. Почти все авторы объясняют эти факты различным количеством Т-лимфоцитов (CD3+) в трансплантате, акцентирую свое внимание на эффекторной субпопуляции Т-клеток (CD3+CD8+). Однако практически нет данных о функциональных различиях в составе другой не менее важной популяции клеток, а именно субпопуляции Т-хелперов (CD3+CD4+), которые ответственны за регуляцию практически всех процессов в Т-клеточном звене иммунной системы. Функциональные свойства Т хелперов - принадлежность к той или иной функционально активной популяции могут быть определены по виду цитокина, который он секретирует при стимуляции его Т-клеточного рецептора (ТКР). Для неспецифической стимуляции ТКР используются суперантигены (сАГ). Использование сАГ вызывает независимую от V $\beta$-домена ТКР, стимуляцию, а также приводят к формированию функционально активных связей между ТКР и главным комплексом гистосовместимости (ГКС) антиген-презентирующих клеток (АПК). Таким образом, под действием сАГ в течение нескольких часов Т-лимфоциты начинают секретировать цитокины, по которым клетку можно отнести к той или иной функционально активной субпопуляции хелперов. Далее нами представлены данные по исследованию функционального состава Т-хелперов трансплантатов, полученных от здоровых доноров.

\section{Пациенты и методы}

В исследование были включены 9 образцов трансплантатов, полученных от здоровых доноров (КМ: n=3, СКК: $\mathrm{n}=6$ ). СКК были получены путем афереза у донора после стимуляции его гемопоэза в течение 5 дней Г-КСФ в дозе 10 мкг/кг. Один миллион клеток полученный из трансплантата в среде RPMI-1640 (в присутствии 10\% аутологичной сыворотки) инкубировали с сАГ в рекомендованной концентрации. В качестве сАГ для стиму- ляции Т- клеток использовали Cytostim (Miltenyi Biotec, Германия). Спустя 2 часа после начала стимуляции с целью выполнения в дальнейшем внутриклеточного окрашивания добавляли блокатор белкового транспорта - брефелдин А. После этого клетки продолжали инкубировать еще в течение 4 часов при $37^{\circ} \mathrm{C}, \mathrm{CO} 2$ - 5\%. В дальнейшем было выполнено внутриклеточное окрашивание согласно стандартному протоколу (Cytofix/ Cytoperm, BD, USA). Для идентификации T-хелперов использовали моноклональные антитела к антигенам CD45-APC , CD4-APC-Cy7, FoxP3-PerCP-Cy5.5, IL-17APE фирмы BD и CD294-FITC фирмы Biolegend, антиINF- $\gamma$-PE-Cy7 (см рисунок 1) (Th1:CD45+CD4+INF- $\gamma+$; Th2:CD45+CD4+CD294+; $\quad$ Treg:CD45+CD4+FoxP3+; Th17:CD45+CD4+IL-17A+). 30000 CD4+ клеток анализировали на проточном цитометре BD FACSCanto II (Becton Dickinson, USA).

\section{Результаты и обсуждение}

Как представлено на рисунке 2 (слева) все образцы костного мозга имеют равное соотношение Th1:Th2:Treg:Th17 клеток, которое не отличается от того, что наблюдается в периферической крови (ПК) здоровых доноров. Вероятно, это связано с тем, что все Т-лимфоциты КМ являются лимфоцитами ПК, попавшими в трансплантат во время эксфузии костного мозга. С другой стороны, в СКК (рисунок 2, справа), все образцы трансплантатов имеют различное соотношение Th1:Th2:Treg:Th17 клеток. Учитывая широкое распространение, которое получило абсолютное количество CD34+ клеток при характеристике трансплантатов в клинической практике, а также исходно различное число ядросодержащих клеток в каждом из трансплантатов, мы рассчитали какое число Th1, Th2, Treg, Th17 клеток приходится на $100 \mathrm{CD} 34+$ клеток (нормализовали на число CD34+ клеток) в КМ (рисунок 3, слева) и СКК (рисунок 3, справа). Как видно из рисунка 3 (справа), соотношение Th1, Th2, Treg, Th17 к CD34+ клеткам в СКК может варьировать (отличаться до 40 раз!) от образца к образцу.

\section{Заключение}

Таким образом, стимуляция Т-лимфоцитов трансплантата сAГ in vitro может отражать те процессы, которые происходят с Т-клетками in vivo после трансфузии, и 


\section{SHORT REPORTS}

может быть использована как модель для изучения влияния функционального состава трансплантата на развитие оРТПХ, отторжения и других процессов, в которых Т-клетки трансплантата принимают непосредственное участие. Наши предварительные данные показывают, что функциональный состав Т-лимфоцитов трансплантата очень вариабелен от образца к образцу и может влиять на процессы, которые происходят в иммунной системе реципиента после трансфузии трансплантата.

\section{Ключевые слова}

Стволовые клетки крови, костный мозг, трансплантат, острая РТПХ, Т хелперы, Th17, Т регуляторные клетки, Th1, Th2. 